Hydrology and Earth System Sciences, 8(5), 931-939 (2004) C EGU

\title{
Analysis of the spatial variation in the parameters of the SWAT model with application in Flanders, Northern Belgium
}

\author{
Griet Heuvelmans, Bart Muys and Jan Feyen \\ Department of Land Management, Katholieke Universiteit Leuven, Vital Decosterstraat 102, B-3000 Leuven, Belgium \\ Email for corresponding author: griet.heuvelmans@agr.kuleuven.ac.be
}

\begin{abstract}
Operational applications of a hydrological model often require the prediction of stream flow in (future) time periods without stream flow observations or in ungauged catchments. Data for a case-specific optimisation of model parameters are not available for such applications, so parameters have to be derived from other catchments or time periods. It has been demonstrated that for applications of the SWAT in Northern Belgium, temporal transfers of the parameters have less influence than spatial transfers on the performance of the model. This study examines the spatial variation in parameter optima in more detail. The aim was to delineate zones wherein model parameters can be transferred without a significant loss of model performance. SWAT was calibrated for 25 catchments that are part of eight larger sub-basins of the Scheldt river basin. Two approaches are discussed for grouping these units in zones with a uniform set of parameters: a single parameter approach considering each parameter separately and a parameter set approach evaluating the parameterisation as a whole. For every catchment, the SWAT model was run with the local parameter optima, with the average parameter values for the entire study region (Flanders), with the zones delineated with the single parameter approach and with the zones obtained by the parameter set approach. Comparison of the model performances of these four parameterisation strategies indicates that both the single parameter and the parameter set zones lead to stream flow predictions that are more accurate than if the entire study region were treated as one single zone. On the other hand, the use of zonal average parameter values results in a considerably worse model fit compared to local parameter optima. Clustering of parameter sets gives a more accurate result than the single parameter approach and is, therefore, the preferred technique for use in the parameterisation of ungauged sub-catchments as part of the simulation of a large river basin.
\end{abstract}

Keywords: hydrological model, regionalisation, parameterisation, spatial variability

\section{Introduction}

Conceptual as well as physically-based hydrological models contain parameters that cannot be measured or quantified directly. These parameters may, for example, control the water movement into and out of model conceptual stores representing soil, groundwater or others, or they may be large-scale equivalents of variables that can be observed only at the point scale, as in the case of soil hydraulic properties. To obtain a reliable model output, parameters should be optimised with respect to locally observed hydrological variables. Such a case-specific model calibration is often not possible in practice because data are lacking. Parameters are then usually transferred from other time periods and/or other catchments. Past analyses have shown that for applications of the SWAT (Arnold et al.,
1998) hydrological model in Flanders, both temporal and spatial transfers of parameter estimates lower the performance of the model, with the decrease being considerably larger for spatial than for temporal transfers (Heuvelmans et al., 2004) (Fig. 1). This study examines the spatial transferability of parameters in more detail.

Andersen et al. (2001) discuss the significance of the spatial variability in parameter optima for a large-scale application of the MIKE SHE model. In their study, the spatially-distributed parameterisation obtained by a multisite calibration leads to a better model fit than the singlesite calibration, treating model parameters as spatially invariant. Wooldridge and Kalma (2001) draw a similar conclusion for the comparison of a lumped and a semidistributed parameterisation of the conceptual VIC model 


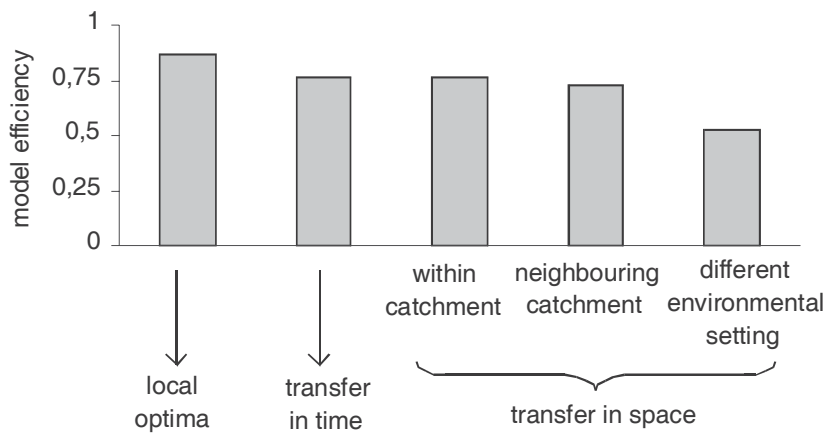

Fig. 1. Effect of parameter transfers in space and time on the model efficiency for daily stream flow simulation in the Nete and the Bovenschelde region, Belgium (Heuvelmans et al., 2004)

structure: the semi-distributed parameterisation results in a better model performance. In general, for large-scale applications of a hydrological model, insight into the spatial variation in parameter optima can improve the performance of a model. Besides, knowledge about the spatial variation in parameter optima may be of use for parameterising ungauged catchments. It can guide the selection of the gauged catchment(s) that is/are hydrologically similar enough to the ungauged site so that the loss of model performance after a transfer of parameters remains acceptable.

The spatial variability of model parameters can be looked at in two different ways: the parameters can be considered one-by-one (single parameter approach) or the entire parameter set can be examined as a whole (parameter set approach). Theoretically, the single parameter approach corresponds to analysing each hydrological process separately, whereas the parameter set approach considers the entire hydrological system at once. Beven (1993) pointed out the importance of a parameter set based analysis. The effect of one parameter on the model output usually depends on the values of the other parameters. This implies that even if a hydrological process is similar for two catchment areas, two completely different parameter optima might be derived for these catchments. Hence, the link between a single model parameter and a particular hydrological process is not always clear. This can hamper the recognition of a spatial pattern in parameter optima.

This study examines the spatial variation in the parameters of the SWAT model within the Flemish part of the Scheldt river basin. Specific objectives are (I) to assess which catchments within the study region are hydrologically similar enough to allow transfers of parameter sets without a significant loss in model performance and (II) to assess which is the most appropriate approach for delineating zones: a single parameter or a parameter set approach. The results can be used for the parameterisation and the hydrological analysis of ungauged sub-catchments in the Scheldt river basin.

\section{Method}

\section{THE STUDY REGION}

The study is limited to the Flemish part of the Scheldt river basin, northern Belgium, covering an area of approximately $20000 \mathrm{~km}^{2}$. The 25 study catchments, ranging in size from $2 \mathrm{~km}^{2}$ to $210 \mathrm{~km}^{2}$, together cover about $7.5 \%$ of the total study area and are scattered over eight larger administrative hydrological units, i.e. eight sub-basins of the Scheldt river basin (Fig. 2). For the sub-basin 'Gentse Kanaalzone' in the north, no discharge data are available so it has been excluded from the analysis. One sub-basin, the Benedenschelde, contains only one study catchment; for all others two to five sub-catchments are simulated.

The study region is relatively small, so climatic conditions are more or less uniform for all the simulated catchments. The region has a temperate climate, with an average annual precipitation of $813 \mathrm{~mm} \mathrm{yr}^{-1}$, a mean July temperature of $16^{\circ} \mathrm{C}$ and a mean January temperature of $2^{\circ} \mathrm{C}$. No dry and wet seasons can be distinguished as the intensity, duration and frequency of rainfall events vary throughout the year. Summer months are characterised by shorter and more intensive storms; in winter more frequent and generally less intensive storms occur. As shown in Table 1, the 25 study catchments cover a wide variation in topographical, pedological, hydrological and land use characteristics.

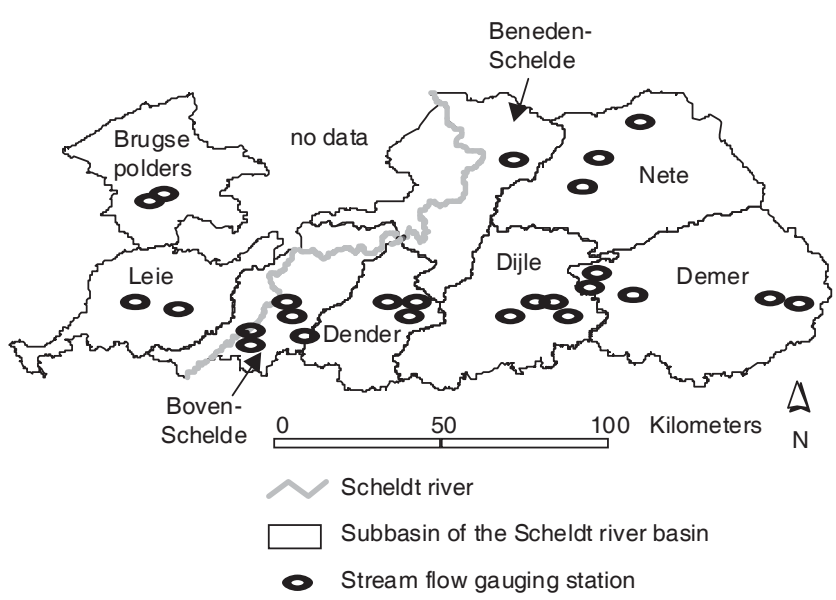

Fig. 2. Location of the 25 study catchments over the eight Scheldt river subbasins 
Table 1. Area, slope, drainage density and dominant soil texture and land use type of the study areas

\begin{tabular}{|c|c|c|c|c|c|c|}
\hline$I D$ & Scheldt river subbasin & Area $\left(\mathrm{km}^{2}\right)$ & Slope (\%) & Height ( $m$ a.s.l.) & Dominant land use & Dominant soil \\
\hline 1 & Benedenschelde & 107.98 & 0.18 & $10-31$ & $\mathrm{~F}$ & $\mathrm{~S}$ \\
\hline 2 & Bovenschelde & 2.68 & 2.65 & $32-91$ & $\mathrm{AL}$ & SL \\
\hline 3 & Bovenschelde & 31.00 & 2.56 & $31-132$ & $\mathrm{AL}$ & $\mathrm{L}$ \\
\hline 4 & Bovenschelde & 111.81 & 2.12 & $11-131$ & $\mathrm{AL}$ & $\mathrm{L}$ \\
\hline 5 & Bovenschelde & 47.86 & 2.81 & $17-150$ & $\mathrm{AL}$ & $\mathrm{L}$ \\
\hline 6 & Bovenschelde & 2.24 & 2.35 & $29-93$ & $\mathrm{AL}$ & $\mathrm{L}$ \\
\hline 7 & Brugse polders & 67.63 & 0.40 & $10-47$ & $\mathrm{P}$ & $\mathrm{S}$ \\
\hline 8 & Brugse polders & 73.93 & 0.33 & $11-42$ & $\mathrm{P}$ & $\mathrm{S}$ \\
\hline 9 & Demer & 64.00 & 1.62 & $13-103$ & $\mathrm{AL}$ & SL \\
\hline 10 & Demer & 37.74 & 1.80 & $35-100$ & $\mathrm{AL}$ & SL \\
\hline 11 & Demer & 15.02 & 2.04 & $15-70$ & $\mathrm{AL}$ & SL \\
\hline 12 & Demer & 99.87 & 1.33 & $43-125$ & $\mathrm{AL}$ & $\mathrm{L}$ \\
\hline 13 & Demer & 27.38 & 0.97 & $48-120$ & $\mathrm{~F}$ & $\mathrm{~S}$ \\
\hline 14 & Dender & 21.23 & 1.82 & $18-91$ & $\mathrm{AL}$ & $\mathrm{L}$ \\
\hline 15 & Dender & 87.43 & 1.74 & $12-95$ & $\mathrm{AL}$ & $\mathrm{L}$ \\
\hline 16 & Dender & 25.90 & 1.63 & $19-90$ & $\mathrm{AL}$ & $\mathrm{L}$ \\
\hline 17 & Dijle & 50.71 & 2.02 & $39-118$ & $\mathrm{AL}$ & $\mathrm{L}$ \\
\hline 18 & Dijle & 39.32 & 2.01 & $27-121$ & $\mathrm{AL}$ & $\mathrm{L}$ \\
\hline 19 & Dijle & 48.22 & 1.60 & $22-101$ & $\mathrm{AL}$ & SL \\
\hline 20 & Dijle & 35.08 & 1.71 & $32-103$ & $\mathrm{AL}$ & SL \\
\hline 21 & Leie & 73.71 & 0.65 & $20-55$ & $\mathrm{AL}$ & SL \\
\hline 22 & Leie & 92.18 & 0.63 & $14-55$ & $\mathrm{AL}$ & SL \\
\hline 23 & Nete & 89.18 & 0.18 & $11-31$ & $\mathrm{AL}$ & $\mathrm{S}$ \\
\hline 24 & Nete & 56.54 & 0.22 & $19-35$ & $\mathrm{~F}$ & $\mathrm{~S}$ \\
\hline 25 & Nete & 209.93 & 0.19 & $13-33$ & $\mathrm{~F}$ & $\mathrm{~S}$ \\
\hline
\end{tabular}

Land use codes: AL: arable land, P: pasture, F: forest

Soil codes: S: sand, SL: sandy loam, L: loam

\section{SWAT MODEL SET-UP}

The SWAT (Soil and Water Assessment Tool), developed by Arnold et al. (1998), is a semi-distributed model that is of particular interest for modelling the impact of land use on catchment hydrology. It relies partly on physical laws, partly on empirical relationships. The physical backbone of the model facilitates the interpretation of model parameters whereas the empirical simplifications keep data requirements low compared to fully physically based models. The simulations discussed in this paper are limited to the water quantity module of the SWAT. For detailed information about the model structure including other model components, the reader is referred to Arnold et al. (1998).

To run the SWAT model, pedological, climatological, hydrological, topographical and land use related data are required. All simulations rely on the same data sources and providers: the Royal Meteorological Institute (KMI) provided climatic data and the Environmental Administration (AMINAL) daily flow discharge measurements for the period 1990-2001. These data sets were divided in an optimisation period (1990-1995) and a validation period (1996-2001). Digital elevation data were obtained from the National Geographical Institute (NGI). Digital soil and land use maps are distributed by the Flemish Land Agency (VLM). Basic soil attributes were derived from the AARDEWERK database (Van Orshoven et al., 1993). Soil hydraulic properties were calculated from these basic soil attributes with the pedo-transferfunctions developed by Vereecken et al. (1990). Land use attributes were taken from the crop database of the SWAT model and adapted to local practice.

Sensitivity tests and preliminary model runs were carried out to identify the most sensitive model parameters. To avoid overparameterisation, only the most sensitive parameters were adjusted in the model calibration. Seven sensitive parameters were identified: four of these mainly affect base flow generation (GW_REVAP, REVAPMN, GW_DELAY, ALFA_BF), the remaining three primarily affect surface 


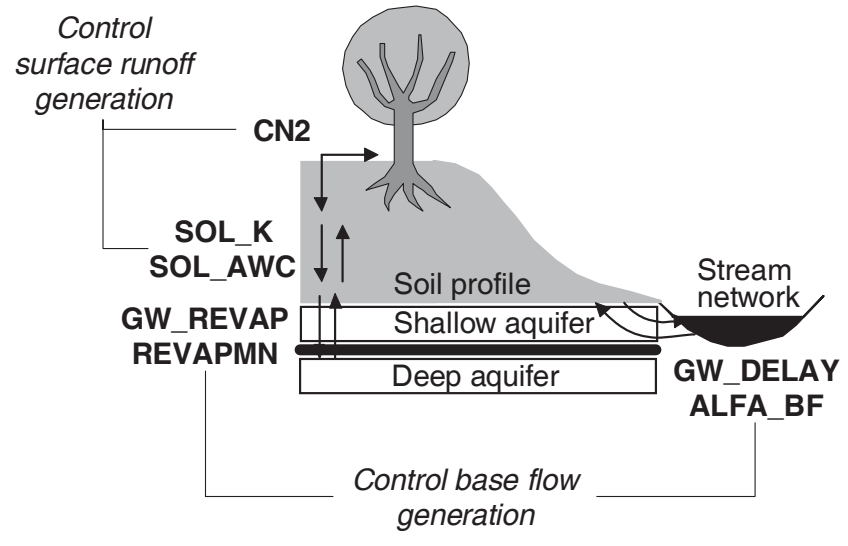

Fig. 3. General overview of the processes simulated by SWAT, and the parameters that control these processes. CN2: SCS Curve Number; SOL K: soil hydraulic conductivity; SOL AWC: soil available water capacity; GW REVAP and REVAPMN: rate of and threshold for 'revap' i.e. water movement between root zone and shallow aquifer; ALFA_BF: recession constant; and GW_DELAY: groundwater delay time.

runoff formation (CN2, SOL_K, SOL_AWC) (Fig. 3). CN2 (dimensionless) is the SCS Curve Number, SOL_K (mm hour $^{-1}$ ) and SOL_AWC ( $\mathrm{mm}$ water/mm soil) respectively are the soil hydraulic conductivity and available water capacity both specified per soil horizon. GW_REVAP is a dimensionless coefficient controlling the rate of water movement between the root zone and the shallow aquifer. It is related to the threshold value REVAPMN being the amount of water (in $\mathrm{mm}$ ) that must be present in the shallow aquifer store before water can move to the unsaturated zone or to the deep aquifer. The response of base flow to changes in recharge of the shallow aquifer is described by the recession constant ALFA_BF (days). GW_DELAY (days) is the time required for water leaving the bottom of the root zone to reach the shallow aquifer.

Model parameters were calibrated manually using the observed daily stream flow values for the period 1990-1995. The surface flow related parameters SOL_AWC, SOL_K and $\mathrm{CN} 2$ were approximated with pedo-transferfunctions and the Curve Number table. These parameter estimation schemes are known to bear a considerable degree of uncertainty and the derived parameter estimates were therefore corrected in the calibration. To keep the calibration manageable, the correction factors that are expressed as a percentage of the values predicted by the Curve Number table or the pedo-transferfunctions, were kept constant throughout a single catchment and, for the soil hydraulic features, for all soil types and soil horizons. For the base flow related parameters, GW_REVAP, ALFA_BF, REVAPMN and GW_DELAY, no a priori parameter estimation scheme is available. These parameters were calibrated from scratch and the exact parameter values were kept constant throughout a single catchment. Two criteria were used to assess the optimal parameter values and correction factors: (I) evaluation of simulated daily stream flow values by means of the model efficiency defined by Nash and Sutcliffe (1970) and (II) evaluation of the simulated average yearly flow components using the average yearly base- and surface flow volumes calculated from the observed daily stream flow time series with the filter of Arnold et al. (1995) as a reference. The filter procedure of Arnold et al. (1995) calculates the quick flow component $\mathrm{q}_{\mathrm{t}}$ at time step $t$ from the total flow $\mathrm{Q}_{\mathrm{t}}$ as follows:

$$
\mathrm{q}_{\mathrm{t}}=\beta * \mathrm{q}_{\mathrm{t}-1}+\frac{1+\beta}{2} *\left(\mathrm{Q}_{\mathrm{t}}-\mathrm{Q}_{\mathrm{t}-1}\right)
$$

where $q_{t}>0$ and filter parameter $\beta=0.925$

This equation is applied three times. In the second and the third pass, the total flow is set to the slow flow component $\left(Q_{t}-q_{t}\right)$ resulting from the first and second pass respectively. The slow flow component of the third pass is a good approximation to the base flow.

The two optimisation criteria were also used to evaluate the model performance for the six year validation period 1996-2001.

\section{DELINEATION OF ZONES WITH A UNIFORM PARAMETERISATION}

The variation in parameter optima within each of the eight sub-basins of the Scheldt river basin is expected to be small compared to the overall variation in parameter optima. Huisman et al. (2003) and van der Linden and Woo (2003) concluded that the difference in parameter optima between nearby catchments is small, so that an exchange of parameter optima between such catchments does not significantly lower the performance of the SWAT-G and the SLURP model respectively. The assumption of uniform parameter optima within each of the eight Scheldt river sub-basins is supported by the observed spatial transferability of parameter sets depicted by the three bars at the right side of Fig. 1: transfers within a catchment and to neighbouring catchments result in a smaller decrease in model performance than transfers to catchments at a greater distance. It can, therefore, be assumed that the hydrological processes within one of the eight sub-basins are similar for all the catchments in that sub-basin. The variation in parameter optima within one of the eight sub-basins can be regarded as the uncertainty in the relationship between a particular hydrological process and a parameter value.

If model parameters do not vary much within each one of the eight sub-basins of the Scheldt river basin, these subbasins can be used as a starting point for the delineation of 
zones of uniform parameterisation. The eight sub-basins are gradually merged into larger clusters in a hierarchical way. At each step, the two clusters with the largest similarity are merged. The similarity measure used is the inverse of the Euclidian distance between the two clusters, calculated with the average linkage method, i.e. the average distance between all samples belonging to the two different clusters (Everitt et al., 1993). Consider $\mathrm{x}=\left(\mathrm{x}_{1}, \mathrm{x}_{2}, \mathrm{x}_{3}, \mathrm{x}_{4}, \mathrm{x}_{5}, \mathrm{x}_{6}, \mathrm{x}_{7}\right)$ and $\mathrm{y}=\left(\mathrm{y}_{1}, \mathrm{y}_{2}, \mathrm{y}_{3}, \mathrm{y}_{4}, \mathrm{y}_{5}, \mathrm{y}_{6}, \mathrm{y}_{7}\right)$ optimal parameter sets in case of the parameter set approach or $\mathrm{x}=\mathrm{x}_{1}$ and $\mathrm{y}=\mathrm{y}_{1}$ optimum values of the parameter under study in case of a single parameter approach. The Euclidian distance $\mathrm{D}\left(\mathrm{C}_{1}\right.$, $\mathrm{C}_{2}$ ) between two clusters $\mathrm{C}_{1}$ and $\mathrm{C}_{2}$ containing $\mathrm{n}_{1}$ and $\mathrm{n}_{2}$ catchments is then calculated as:

$$
\mathrm{d}(\mathrm{x}, \mathrm{y})=\left|\mathrm{x}_{1}-\mathrm{y}_{1}\right|
$$

for the single parameter approach

$$
\mathrm{d}(\mathrm{x}, \mathrm{y})=\sqrt{\left|\mathrm{x}_{1}-\mathrm{y}_{1}\right|^{2}+\left|\mathrm{x}_{2}-\mathrm{y}_{2}\right|^{2}+\ldots+\left|\mathrm{x}_{7}-\mathrm{y}_{7}\right|^{2}}
$$

for the parameter set approach

$$
\mathrm{D}\left(\mathrm{C}_{1}, \mathrm{C}_{2}\right)=\frac{1}{\mathrm{n}_{1} * \mathrm{n}_{2}} * \sum_{\substack{\mathrm{x} \in \mathrm{C}_{1} \\ \mathrm{y} \in \mathrm{C}_{2}}} \mathrm{~d}(\mathrm{x}, \mathrm{y})
$$

The hierarchical merging of clusters is interrupted when the ratio of the within-cluster variation in parameter optima to the between cluster variation gets too large. For the single parameter approach, the Kruskall-Wallis test, a nonparametric test for comparing two or more groups of observations of one variable, was used to evaluate whether the parameter optima of one particular cluster differ significantly from those of a second cluster. Because of the multidimensionality of the data, this simple statistical test could not be applied in the parameter set approach without modifications. In this approach, a principal components analysis (PCA) was executed to detect the main gradients in the dataset of the optimal parameter sets for the 25 catchments. The PCA-axes are linear combinations of model parameters with the first axis explaining most of the variation between the parameter sets, the second axis the second most, etc with subsequent axes orthogonal to all preceding ones. Hence, the scores of the parameter sets on the first and the second axes summarise the parameter sets such that the most pronounced differences in parameterisation are still detectable. Therefore, two clusters are considered significantly different in the parameter set approach if a Kruskall-Wallis test points out a significant difference in the scores on the first or the second PCA-axis.

\section{Results and discussion}

\section{MODEL CALIBRATION AND EVALUATION}

The model efficiency for daily stream flow simulation of the 25 catchments varies between 0.95 and 0.70 for the calibration period 1990-1995. To enable the delineation of zones with a uniform parameterisation, parameter optima should be robust. A first indication of the robustness of the parameter optima is the drop in model efficiency after transfer of the parameter estimates from calibration (1990$1995)$ to validation (1996-2001) period. Overall, the loss in model efficiency is smaller than $10 \%$; it is even smaller than 5\% for most catchments (Fig. 4). For two catchments, the model efficiency during the validation period is slightly better than for the calibration period.

The model efficiency differs substantially throughout the study region. In the northern part of the area, the model performs worst. This region has flat topography and is transected by several large artificial canals, complicating the delineation of the area draining to the river network. However, the model efficiency is still acceptable and the difference in model efficiency between the calibration and validation periods is rather small and acceptable (2-4\%). It can, therefore, at least to some extent be assumed that parameter optima are robust and reflect the prevailing hydrological processes.

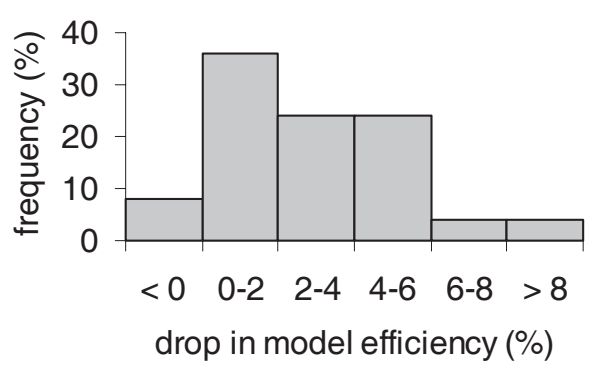

Fig. 4. Loss in model efficiency for daily stream flow simulation after transfer of parameters from the calibration (1990-1995) to the validation (1996-2001) period for the 25 study catchments

\section{SPATIAL VARIABILITY IN PARAMETER OPTIMA}

As expected, the variation in parameter optima within each of the eight sub-basins of the Scheldt river basin is small compared with the overall variation between the eight subbasins (Table 2). Consequently the eight sub-basins are suitable starting points for the delineation of zones with a uniform parameter set. 
Table 2. Variation in parameter optima between (overall variation) and within the eight subbasins of the Scheldt river basin

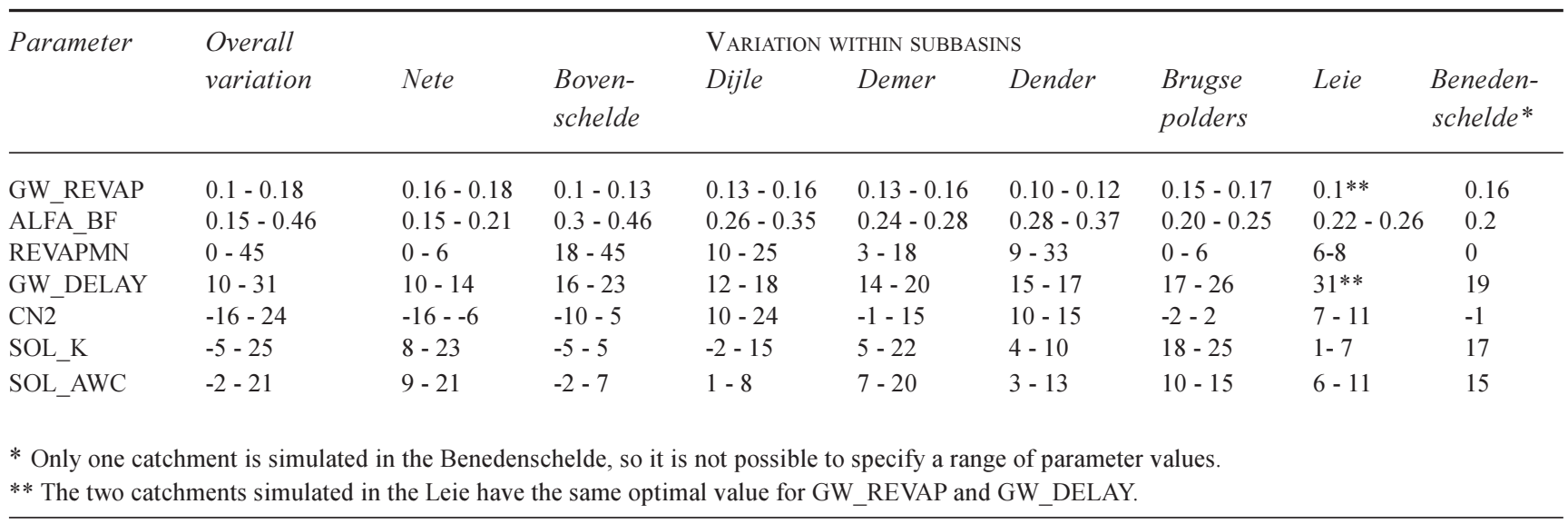

\section{Single parameter approach}

Figure 5 depicts the zones delineated following the single parameter approach. For all parameters, two to four zones with significantly different parameter optima can be identified if the confidence level is set at 0.05 .

The parameters GW_REVAP and REVAPMN, both controlling water movement between soil profile and shallow aquifer, clearly show a North-South gradient. This means that water will re-enter the soil profile more easily through capillary forces in the northern part of the study region, probably because the water table depth is relatively shallow compared to that in the southern part of the study region. Besides, the larger GW_REVAP and smaller REVAPMN values in the north might be due to a difference in land use; more forested areas occur in the north, especially in the Nete and the Benedenschelde; having a greater rooting depth than other land use types, it is more likely that water from a shallow aquifer is lost by evapotranspiration. This hypothesis is supported by the fact that the catchments with a larger area under forest in the south (Demer and to a lesser extent Dijle), have relatively large GWREVAP and small REVAPMN values. Note that in contrast to climate or geology, land use does not always vary consistently between locations; consequently it is not unexpected that a regionalisation based on landscape attributes may outperform one based on location.

The parameters controlling baseflow ALFA_BF and GW_DELAY both follow an East-West gradient. This pattern is hard to explain in physical terms. Because these parameters control water flow between the soil profile and the river system, they may well be related to subsurface characteristics presently unknown, so that the location of a catchment can be considered as a proxy for these unknown features. One can, therefore, foresee that a regionalisation based on landscape attributes would be less successful for
ALFA_BF and GW_DELAY than a location-based regionalisation.

In general, pedo-transferfunctions which are developed at the point scale have the tendency to underestimate soil hydraulic properties, probably because they do not consider the effect of heterogeneities like preferential flow paths that affect the soil hydraulic behaviour at larger spatial scales. For the correction factors of the surface flow related parameters SOL_K, SOL_AWC and CN2 two different zones can be distinguished. The Northern part of the study area is characterised by higher correction factors for the soil hydraulic features and a relatively small or even a negative correction factor for the Curve Number CN2. This spatial pattern may reflect a difference in runoff generating mechanisms between the zones; in the north, soils have a high infiltration capacity and overland flow occurs only when soils are saturated, whereas in the south overland flow occurs more often.

\section{Parameter set approach}

Figure 6 presents the outcome of the principal component analysis. The first and the second PCA axis explain respectively $58 \%$ and $31 \%$ of the variation in parameter optima, justifying the decision to interrupt the merging of parameter set clusters if the scores on the first or the second PCA-axis are not significantly different. Figure 7 depicts the three zones delineated following the parameter set approach and their distribution in parameter space is shown in Fig. 6. The average parameter optima for the three zones are given in Table 3.

The results of the parameter set approach are more difficult to interpret in physical terms than the single parameter analysis. The parameters set based zones correspond roughly with the North-South gradient that is observed for five out of seven model parameters in the single parameter approach; 
GW_REVAP

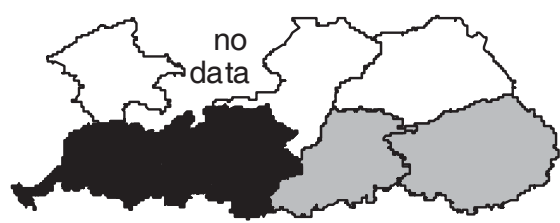

Average parameter value (dimensionless): $\begin{array}{cc}\square & 0.11 \quad 0.14 \quad \square 0.16\end{array}$

\section{REVAPMN}

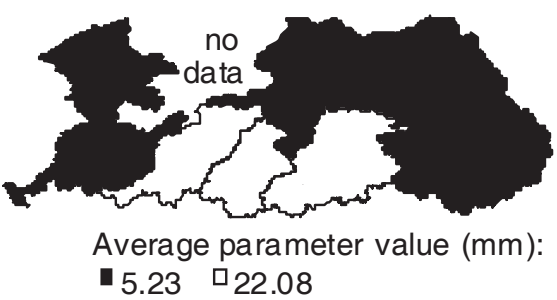

GW_DELAY

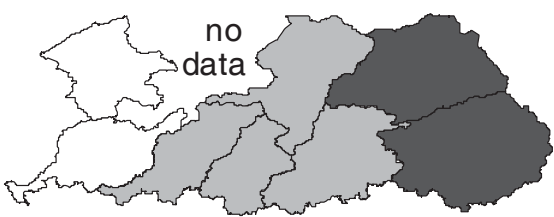

Average parameter value (days):

$\square 13.3 \square 17.6 \square 28.0$

\section{ALFA_BF}

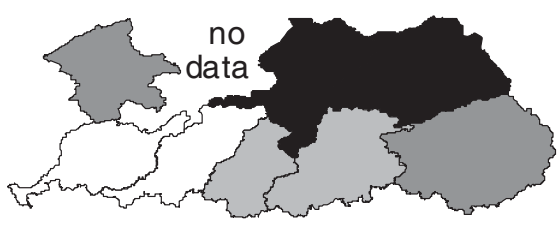

Average parameter value (days):

- $0.19 \square 0.25 \square 0.32 \square 0.38$
SOL_K

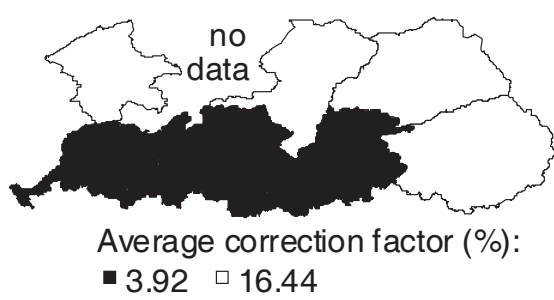

SOL_AWC

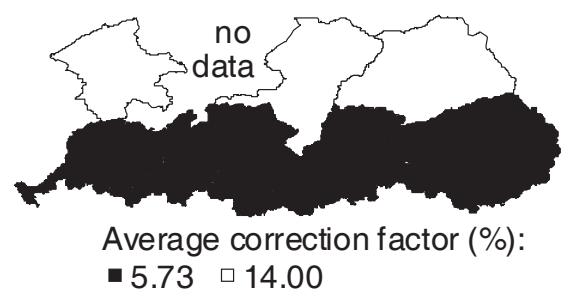

CN2

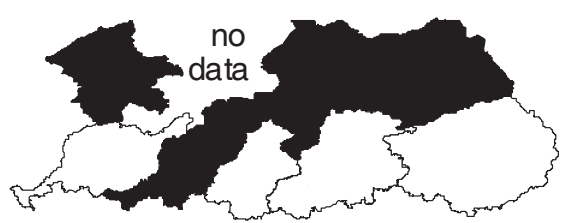

Average correction factor (\%):

- $-5.46 \square 10.57$

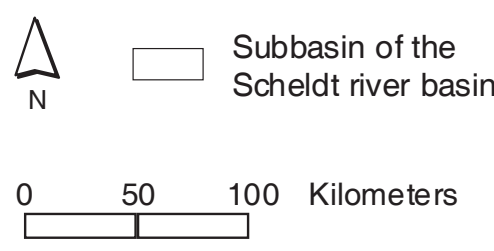

Fig. 5. Zones with a uniform parameter optimum delineated with the single parameter approach. Parameter definitions are given in Fig. 3

Table 3. Average parameter optima for the zones delineated with the parameter set approach

\begin{tabular}{llll}
\hline Parameter & Zone I & Zone II & Zone III \\
\hline GW_REVAP & 0.15 & 0.1 & 0.12 \\
REVAPMN & 5 & 7 & 20 \\
ALFA_BF & 0.21 & 0.24 & 0.34 \\
GW_DELAY & 17 & 31 & 16 \\
SOL_K & 2.7 & 4.1 & 6.9 \\
SOL_AWC & 11 & 8 & 4 \\
CN2 & 12 & 9 & 4 \\
\hline
\end{tabular}

hence the parameter set based zones most probably have a physical basis comparable with those explained above. This physical explanation refers to a catchment's abiotic properties, and does not relate directly to land use. According to the information in Table 3, zone I in the north and zone III in the south represent the extremes of most parameter values, whereas zone II, consisting of only the Leie subbasin, lies somewhere in between. One might question whether it is correct to consider the Leie sub-basin, where only two catchments are modelled, as a separate parameter set zone. The principal components analysis (Fig. 6), 


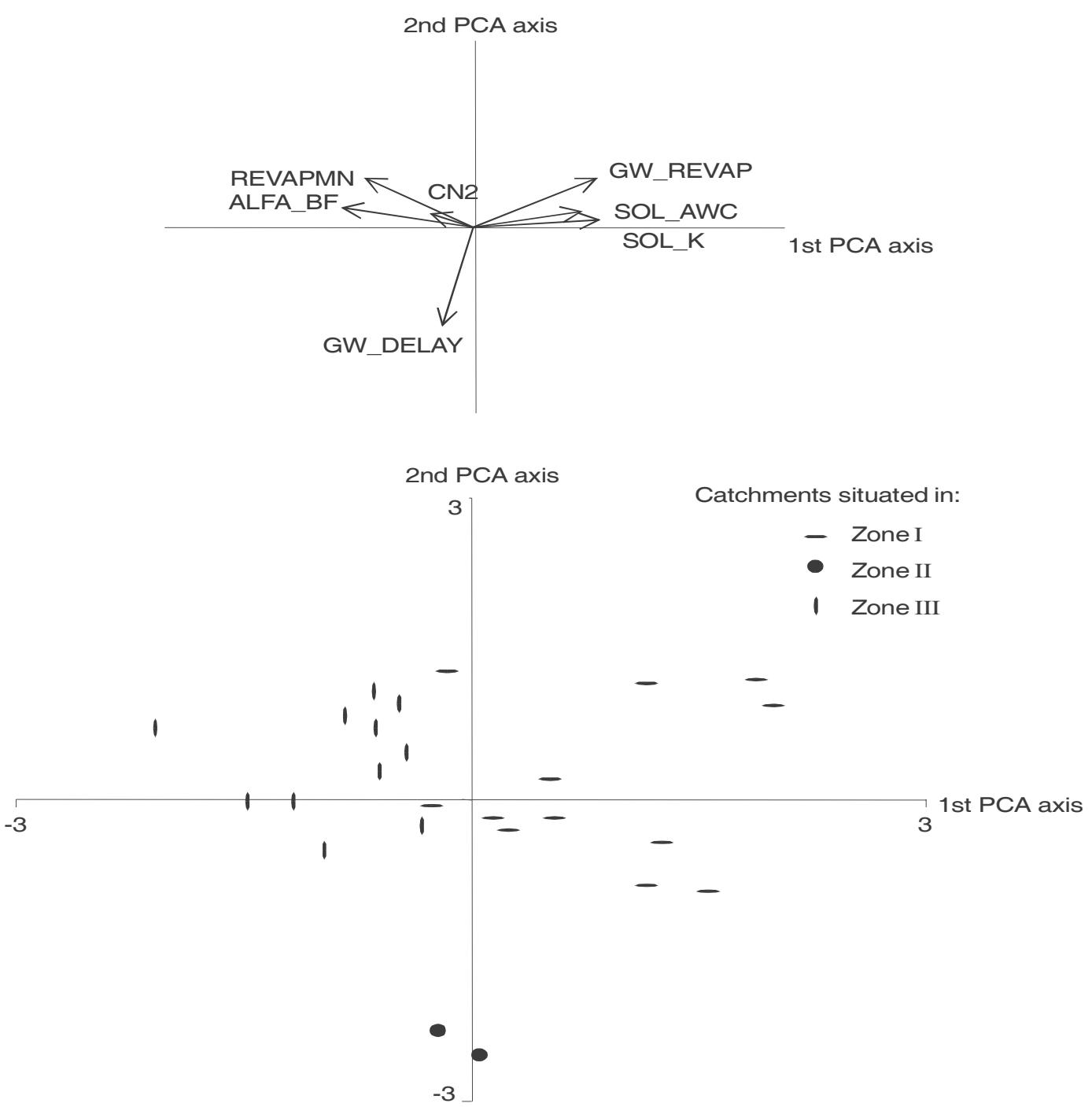

Fig. 6. Results of the PCA analysis: correlation of model parameters with the first and the second PCA axis and location of the study catchments in parameter space. Parameter definitions are given in Fig. 3

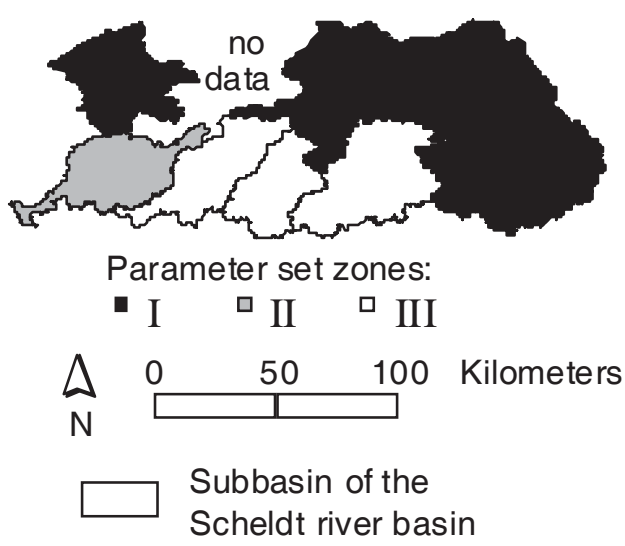

Fig. 7. Zones with a uniform parameterisation delineated with the parameter set approach however, indicates that the two catchments in the Leie subbasin have a very similar set of parameters and at the same time this graph reveals that the parameterisation as-a-whole in the Leie clearly differs from all the other sites.

Comparing the performance of the single parameter and the parameter set approach

The performance of the two parameterisation strategies is evaluated by making four SWAT model runs for every catchment studied: (I) with the local parameter optima for the catchment under study (LOC); (II) with the region-wide average parameter optima for the 25 study catchments (REG); and with the average parameter optima for the zones delineated with the (III) single parameter (SIN) and (IV) parameter set (SET) approach. Figure 8 compares the model 


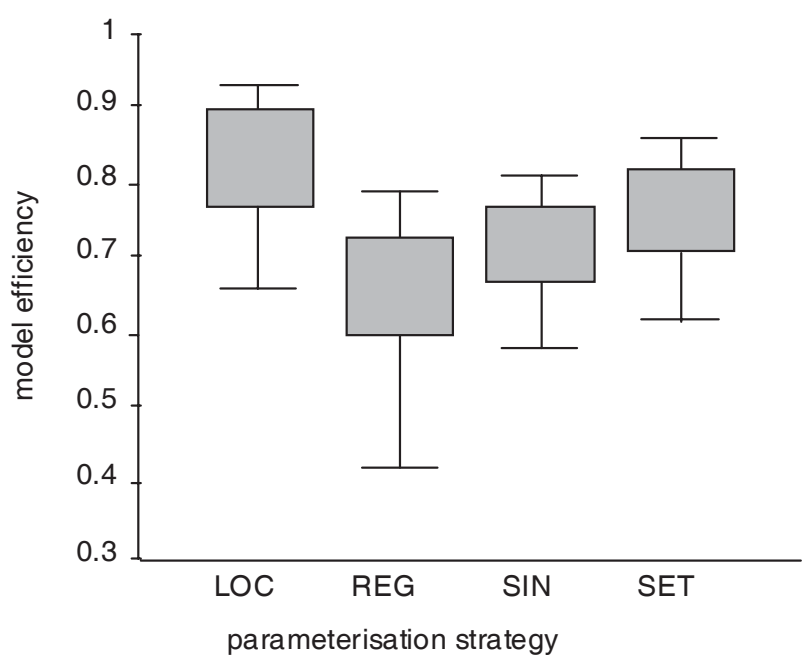

Fig. 8. Evaluation of the model efficiency for daily stream flow simulation using four different parameterisation strategies: using local parameter optima for every catchment (LOC), using the region-wide average parameter optima (REG), and using the average parameter optima of the zones delineated with the single parameter (SIN) and the parameter set (SET) approach

efficiency for daily stream flow simulation for these four different parameterisation strategies.

Local parameter optima (LOC) outperform all other parameterisation strategies. Both zonation techniques (SIN and SET) deliver more effective parameter estimates than considering the entire study region as one single zone using the region-wide parameter optima (REG). This indicates that both zonation techniques deliver a useful scheme for the parameterisation of ungauged catchments within the Scheldt river basin. For the given study area, treating the parameter set as a whole (SET) leads to more effective parameter estimates than a per parameter zonation (SIN). Hence, it can be concluded that the parameter set approach is to be preferred in operational model applications.

\section{Conclusion}

For all calibrated model parameters, as well as for the parameter set as a whole, two to four zones with uniform parameterisation are delineated. The observed spatial variation in parameter optima is sometimes hard to explain in physical terms, particularly for the parameter set approach. Nevertheless, the parameter set based approach delivers parameter estimates giving a higher model efficiency than the single parameter approach, which is easier to understand in physical terms. Therefore, to achieve a physically understandable and an effective parameter regionalisation, both zonation techniques should be applied independently and interpreted in combination. The results of the single parameter analysis can be helpful in understanding and evaluating the outcome of the parameter set approach because these results might help to assess the physical soundness of the parameter set groups. Operationally, the parameter set approach is to be preferred as it results in higher model efficiency.

The regionalisation schemes presented in this paper can be used for (I) large-scale simulations because they provide the means for a spatially distributed parameterisation and (II) to enable the estimation of parameters for large- or smallscale simulations of ungauged catchments. In both cases, the schemes can be used only for model applications within the Flemish part of the Scheldt river basin.

\section{References}

Andersen, J., Refsgaard, J.C. and Jensen, K.H., 2001. Distributed hydrological modelling of the Senegal River Basin - model construction and validation. J. Hydrol., 247, 200-214.

Arnold, J.G., Allen, P.M., Muttiah, R. and Bernhardt, G., 1995. Automated base flow separation and recession analysis. Ground Water, 33, 1010-1018.

Arnold, J.G., Srinivasan, R., Muttiah, R.S. and Williams, J.R., 1998. Large area hydrologic modeling and assessment. Part 1: Model development. J. Amer. Water Resour. Assoc., 34, 73-89.

Beven, K., 1993. Prophecy, reality and uncertainty in distributed hydrological modelling. Adv. Water Resour., 16, 41-51.

Everitt, B.S., Landau, S. and Leese, M., 1993. Cluster analysis (3rd edition). Arnold, London, UK. 170pp.

Heuvelmans, G., Muys, B. and Feyen, J. 2004. Evaluation of hydrological model parameter transferability for simulating the impact of land use on catchment hydrology. Phys. Chem. Earth, 29, 739-747.

Huisman, J.A., Breuer, L., Eckhardt, K. and Frede, H.-G., 2003. Spatial consistency of automatically calibrated SWAT simulations in the Dill catchment and three of its sub-catchments. TWRI technical Report 266: Proc. $2^{\text {nd }}$ Int. SWAT conference. $168-173$.

Nash, J.E. and Sutcliffe, J.V., 1970. River flow forecasting through conceptual models, I, A discussion of principles. J. Hydrol., 10, 282-290.

van der Linden, S. and Woo, M.-K., 2003. Transferability of hydrological model parameters between basins in data-sparse areas, subarctic Canada. J. Hydrol., 270, 182-194.

Van Orshoven, J., Deckers, J.A., Vandenbroucke, D. and Feyen, J., 1993. The completed database of Belgian soil profile data and its applicability in planning and management of rural land. Bull. Rech. Agron. Gembloux, 28, 197-222.

Vereecken, H., Feyen, J. and Maes, J., 1990. Estimating the hydraulic conductivity soil water content relationship from easy to measure soil properties. Soil Sci., 149, 1-12.

Wooldridge, S.A. and Kalma, J., 2001. Regional scale hydrological modelling using multiple-parameter landscape zones and a quasi-distributed water balance model. Hydrol. Earth Syst. Sci., 5, 59-74. 